\title{
A Moral Consideration of Corporate-Social-Responsibility (CSR) on the Basis of the Conception of Stephen R. Perry's Risk, Harm, and Responsibility
}

\author{
Vincent Heidinger \\ University of Graz
}

The goal is to develop a moral consideration of CSR. The nature of risk is examined and a distinction in epistemic conception of probability is introduced. The central question, namely if agent-imposed risk has to be regarded as a form of damage in its own right is introduced and applied to the issue of CSR. The modified question if corporation-imposed risk on society can be viewed as a form of damage comes into play. The terms of avoidability and foreseeability are added to the moral concept. The goal is to show that corporations hold a certain responsibility to society.

Keywords: corporate-social-responsibility, nature of risk, agent-imposed risk, corporate-imposed risk, avoidability, foreseeability

\section{INTRODUCTION}

The main goal is to develop an adequate moral consideration of CSR. In order to be able to do so, in the first section, Stephen R. Perry's article on Risk, Harm, and Responsibility will be looked at in great detail. There, the nature of risk is examined and a distinction between (a) an objective and (b) an epistemic conception of probability is introduced. Based on this differentiation the moral significance of a conception of risk comes to light. Then, the central question of his investigation, namely if agent-imposed risk, understood in objective terms, has to be regarded as a form of damage in its own right will be introduced and applied to the issue of CSR. Here, the slightly modified question if corporation-imposed risk on society can be viewed as a form of damage (either to individuals or to society) comes into play. In addition to this, van de Poel and Fahlquist's article on Risk and Responsibility is of great importance for further examination. Ultimately, the terms of avoidability and foreseeability are added to the moral concept and are relevant to estimate the CSR with regard to actions and decisions taken by corporations. The goal is to show that corporations hold a vast responsibility to not only their stakeholders, but to society and the environment in general. Perry's finding of being responsible only for actual harm is highly relevant in this regard.

\section{RISK, HARM, AND RESPONSIBILITY}

\section{Elaboration of the Nature of Risk, Harm, and Responsibility}

In the first section of this essay, the ideas and results of Perry are examined and analyzed. This is necessary to open up the discussion, and to examine whether his findings can be linked to a moral consideration of CSR. To do so, it is essential to take a look at all three relevant terms - that are risk, harm, and responsibility - and he starts with a plain explanation of risk. The nature of risk, hence, can be described 
as the product of probability of the occurrence of harm and the magnitude of it. Therefore, a conduct is said to be risky "when it gives rise to a chance of a bad outcome" (Perry, 1995, 322). Other authors, among others Steve Rayner, have proposed a more sophisticated adaption. Rayner adds the product of trustworthiness of the institution, acceptability of the principle used to apportion liabilities for undesired consequences, and acceptability of the procedure by which collective consent is obtained to those who have to run the consequences (van de Poel \& Fahlquist, 2012, 882; see Rayner 1992). This addition can be helpful to elaborate moral significance of CSR in a later stage, as it is an attempt to include aspects relevant "for the (moral) acceptability of risk" (van de Poel \& Fahlquist, 2012, 882). Coming back to Perry, harm is simplistically depicted as a setback to an interest, while probability contains a more sophisticated approach. It is divided in (a) an objective and in (b) an epistemic conception. First, (a) leads to an understanding of probability that emerges from the relative-frequency theory that can be described as the occurrences of a given attribute within a series of events. This form of probability is regarded a certain empirical knowledge that emerges from the current facts and past events. As this form of probability plays an important role in the analysis of corporate actions and decisions. The main question for corporation leaders is if a certain action is known to bring forth negative consequences to society or to a certain set of individuals. Moreover, as corporations are often mainly driven by economic factors, aspects of the cost-benefit ratio have to be considered. Second, (b) "is best understood in terms of [...] the reasonableness account" (Perry, 1995, 325), which contains two assumptions: (i) that objective probabilities as described in (a) exist, and (ii) that human beings possess "valid standards of inductive reasoning and rational beliefs that are pragmatically justified and permit them to realize such relative frequencies" (ibid.). Again, this is of high relevance in connection to CSR. As corporations are to be understood as a set of people that follow similar interests, those people need to take actions based on a set of certain beliefs and values. Additionally, there is a sense of rationality involved and the economic results and goals must not be neglected. Corporations need to consider their actions in correlation to possible economic benefits and revenue. However, the social responsibility of corporations has to have a place in the consideration before taking actions that might be harmful to society or to certain individuals. On this occasion, the question arises if single individuals or corporations as a set of individuals act. As of limited space within this essay, this question cannot be answered but within the literature of collective responsibility more details to this regard can be found. As a result, "[e]pistemic probability judgements are [...] estimates of objective probabilities that are based on a given body of evidence" (ibid.). This evidence, again, can be established through plain facts or through estimates for future outcomes based on past events. Corporations need to consider both of the mentioned aspects and we will come back to this in a later stage of this essay. Such epistemic probability judgements are capable of expressing a certain knowledge about the world, which is both helpful and critical. Leaving this ambiguity aside, as it would consume too much space, it is essential to state that both (i) and (ii) must be granted truth "if a conception of risk based on the epistemic probability conception is to have moral significance" (Perry, 1995, 326). Only then actions taken by corporations are concerned with real possibilities of harm and are capable of being estimated by the reasonableness account of human beings within the corporation.

\section{The Connection of Risk and Responsibility}

In the second part of this section, I now want to focus on the close connection of risk and responsibility, which represents the bridge to an actual moral significance of CSR, which will be dealt with in section two. It is only natural to think that moral responsibility for corporations should take the form of responsibility only for harm that manifests itself in a fact-based setback of interests. This can either be any form of physical harm (due to contamination of air or water as of irresponsible corporation-behavior) or economic harm, e.g. as a result of maleficent or negligent dealing with the money of investors, or many other manifestations of actual harm. As of the findings by Perry, the mere risk "cannot be regarded as harm in its own right" (Perry, 1995, 339), which is essential for the assessment of corporations' responsibility for risk. Following this, responsibility of actual harm is concerned with two considerations: (I) "that responsibility is concerned with conduct that was risky in the objective sense" (Perry, 1995, 340), which is related to the antecedent knowledge of potential foreseeability of negative outcomes, and (II) that "responsibility is concerned with conduct that was risky in the epistemic sense" (ibid.). A link can be made to the Libertarian 
argument that says that if one chooses to act, one is "both fully entitled to whatever gains one may take and fully responsible for whatever harms one may suffer or cause" (Perry, 1995, 340; see Nozick, 1974, 71). This claim is premised on a unique understanding of the moral significance of action, namely that one can choose whether to become active or to stay passive. This concept of moral significance is both highly discussable, but even more important for this essay, not applicable with regard to CSR. As corporations have to take initiatives to increase their profits, the aspect of passivity does not hold. Moreover, Perry introduces a strong counter argument based on Holmes that states as the reason for making any performance or taking any decision requires the premise that "the [agent] should have made a choice" (see Perry, 1995, 341; Holmes, 1881, 95). This different understanding of moral significance of action suggests that not the choice itself contains the moral significance, but the choice accompanied by the power and ability to avoid the resulting consequences of bringing forth different consequences, which are two important additional aspect for CSR elaboration.

\section{AN APPLICATION TO CSR}

\section{Moral Responsibility of Corporations}

Applied to corporations, this means that there is a certain moral significance to CSR whenever a decision is made. The capacity to avoid negative outcomes is what gives rise to moral responsibility for actual harm and CSR. To which extent this moral significance for CSR is to be taken will be examined in the following section. The significant component of this concept is that the human condition is such that everyone must choose to act in some way or another. The passivity account does not hold as even staying passive is represented as an active choice. Therefore, even the decision to not interfere and to remain passive is morally equivalent to an act, precisely as it is a voluntary decision. This aspect goes back to the freedom condition, already mentioned by Aristotle. There it was said that the freedom condition is given when an agent was not compelled to act in a certain way or to bring about a certain outcome (van de Poel \& Fahlquist, 2012, 884; see Aristotle, 2000). Two aspects which contribute to this concept of moral responsibility are (A) avoidability and (B) foreseeability. While (A) must look to a subjective capacity to avoid harm, (B) takes a smaller step stating that "an agent is unable to avoid harm unless [one] can foresee it" (Perry, 1995, 343). "In the absence of foreseeability, the harm is just an unfortunate upshot of the action taken" (ibid.). However, this foreseeability is closely tied to an appropriate interpretation of the earlier mentioned reasonableness account of epistemic probability. Therefore, the capacity to foresee harm in order to avoid it, is commonly and most appropriately understood as the general ability of connecting an action that either has already caused harm once or, based on certain facts, will inevitably cause harm in the future. If this reasonableness account holds, one is culpable and morally responsible for the action. This, too, has a connection to Aristotle and his knowledge condition, in which it is said that the acting agent knew, or at least could and should have known that a certain action would bring forth a certain undesirable outcome (van de Poel \& Fahlquist, 2012, 884; see Aristotle, 2000). According to Perry, however, if foreseeability is not given, the result is a form of responsibility for unintentional harm which can be described as "outcomeresponsibility" (Perry, 1995, 345). This form is "less blameworthy than culpability" (ibid.) and has a rather consequentialist approach in mind as it focuses on responsibility for harmful outcomes rather than on responsibility for actions as such. To conclude this paragraph and to transfer to actual CSR, it is important to state that moral responsibility for consequences of risky conduct have to be considered as outcomeresponsibility and that foreseeability of harm ought to be considered a necessary condition of actual liability. The question that now calls for an answer is to which extent CSR has moral significance to negative outcomes and what are the responsibilities of any corporation "[w] Poel \& Fahlquist, 2012, 878)?

\section{The Factor of Uncertainty}

Here, the conception of risk again "refers to the situation in which possible outcomes are known and the probabilities [...] of occurrence of these outcomes are known" (van de Poel \& Fahlquist, 2012, 880). Nonetheless, this depiction of risk appears to be tricky as Perry suggested that the term of 'risk' in itself 
contains a certain factor of uncertainty. Therefore, risk cannot be fully known or a level of uncertainty with regard to the probability of the occurrence is antecedently available. As a result, "[r]isk may then be seen as a specification of the notion of harm" (ibid.). Whenever a corporation acts, there is a certain risk to the potential outcome - be it financial consequences, results felt within society, or environmental effects - that evolve around concerns. Those concerns that have close relations to CSR are "the balance and distribution of benefits and risk (over different groups and over generations), and the availability of alternatives" (van de Poel \& Fahlquist, 2012, 881) as the risk-benefit ratio has a strong claim in economic considerations and the availability of alternatives asks the question whether it is affordable for a corporation to implement more expensive alternatives in order to lower a certain risk. Here it surfaces that both the risk-benefit and the cost-benefit calculation play an important role in corporate considerations on risk assessment. To be able to increase the actual CSR and its implementations and to decrease potential negative outcomes, the set of values for which a corporation stands has to be weigh heavier than the prospect of economic revenue it might gain from a riskier conduct. To further elaborate responsibility as such, a distinction between forward- and backward-looking responsibility is introduced. While backward-looking responsibility is mainly concerned with the application of legal terms when something has already happened and "when a risk has materialized" (van de Poel \& Fahlquist, 2012, 883), forward-looking responsibility is more relevant in the assessment of CSR. One major aspect of this is "responsibility-as-obligation" (ibid.) as corporations are responsible for e.g. the safety of their costumers or their money. A corporation, to some extent, is responsible for guaranteeing a safe handling of whatever good or service it provides. Therefore, the forward-looking responsibility within CSR is concerned with the "prevention, [reduction,] and management of risk" (ibid.). The obligation "to avoid risks" (van de Poel \& Fahlquist, 2012, 885) is opposed to "the advantage of certain risky activities" (ibid.). The ambivalence of corporations comes to light. On the one hand, most profit-orientated corporations follow the aim of revenue-maximization to provide economic profit to their stakeholders. On the other hand, every corporation and its tied values yield responsibility to society and the environment, which must not be disregarded. As a result, a mere capitalistic point of view is not enough and a more sustainable and 'social' perspective need to be implemented. But where to draw the line? Both controllability and voluntariness are relevant aspects for the "perception of risk" (ibid.) and are connected to the mentioned above conceptions off freedom and knowledge. Every action has to be taken on a voluntary account (at least to some degree) and the factor of control contributes to the ultimate decision. Rayner adds a moral connotation to the acceptability of risk (see van de Poel \& Fahlquist, 2012, 886) which must not be overseen. As decisions are made by human beings (even within a corporation setting) moral guidance has to be considered and the risk-benefit ration must exceed the simple economic cost-benefit ratio. Many more people and even the environment call out for consideration and especially multinational corporations hold a large responsibility for their actions. Two general conclusions offered are that "people can [...] take or assume forward-looking responsibility [, especially responsibility-as-obligation,] for risks" (van de Poel \& Fahlquist, 2012, 886) and that "the acceptability of risks appear to depend [...] on whether someone can fairly be held responsible for the risk occurring or materializing" (ibid.). Three subdivisions of forward-looking responsibility are introduced - namely, responsibility of risk reduction, responsibility of risk assessment, and responsibility of risk management - of which I want to focus on the last two with regard to CSR. Therefore, the chapter of Risk Assessment Versus Risk Management is looked at in greater detail.

\section{Risk Management}

This part of section two provides good insights on how to assess a certain risk from a corporation's point of view and tries to answer the question of the moral consideration of CSR in risk management. The division of "responsibility for establishing the magnitude of risk (risk assessment) and the decision about the acceptability and management of risk" (van de Poel \& Fahlquist, 2012, 888) are focused on, which gives a hint on how to distinguish these two aspects. The first problematic facet of this elaboration is the value judgement with regard to risk. Is it even possible for risk assessment to be "completely value free" (van de Poel \& Fahlquist, 2012, 889) or does it need "to rely on at least some value judgements" (ibid.)? As discussed earlier, the set of values of a corporation contribute to the risk assessment of actions. As risks 
are by definition "undesirable, classifying something as a risk already involves a value judgement" (ibid.). If a corporation primarily focuses on the maximization of revenue, higher social and environmental risks might be voluntarily taken to increase the financial prospects. However, as every corporation holds a responsibility for society in general, the materialization of high risks may not be acceptable by society and backfire in huge financial losses and in loss of trust. Theoretically, risk assessments must fulfill the criteria of investigating "all potential risk" (ibid.), which is impossible on a practical basis. A selection of potential risks will be included, while others will be disregarded. This, evidently, "implies a value judgement" (ibid.). Here, the problem of undetected risk reaches the surface as "it does not follow that [such risks are] also socially or morally unimportant or irrelevant" (ibid.). All materialized risks "have important consequences for society" (ibid.) when they manifest themselves. As a result, the estimation of risk from a corporation's perspective shows problematic and vague calculations rather than reliable results. This "has important consequences once one takes into account the social ends for which risk assessments are used" (ibid.). "If a risk assessment wrongly declares something not to be a risk while it actually is a serious risk, or vice versa, this may lead to huge social costs, both in terms of [potential] fatalities and economic costs" (ibid.). Where does this leave us? It is crucial to not leave aside scientific and statistical approaches on risk estimation and assessment. Moreover, the relevance of value judgments on a corporation level must not be ignored. Evidently, "one should opt for a joint responsibility of risk assessors and risk managers for making the relevant value judgements while at the same recognizing their specific and different responsibilities" (van de Poel \& Fahlquist, 2012, 890).

\section{CONCLUSION}

In section one, it was investigated on a theoretical basis how to view responsibility with regard to risk in general terms. Perry offers a good overview (combined with well-established insights) that the terms of probability, magnitude, and manifestation of risk contribute to the conception of responsibility in the first place. Rayner adds the aspects of trustworthiness and acceptability to this conception that play an important role in CSR. In section two, van de Poel and Fahlquist contribute to the actual application of the theoretical conception to CSR and it is elaborated that risk assessment and risk management inevitably include value judgements. Such value judgements and the set of values presented and lived out by corporations are the crucial aspect of CSR and represent highly discussed topics in the literature. It is evident that corporations hold a manifold responsibility not only to shareholder or costumers, but to society and the environment in general, too. It is an important fact to mention that this essay can only give a glimpse on the difficulty of this issue but the main aspect of the moral consideration of CSR is investigated: corporations cannot deny the responsibility they hold and a profound assessment of risk and a valid risk management are substantial for corporations to thrive - not only from on economic point of view, but with regard to social and environmental aspects, as well.

\section{ACKNOWLEDGMENT}

I especially want to thank Dr. Adriana Placani of the University of Graz for her wise and insightful guidance. Her support and assistance pushed me to sharpen my thoughts and to finish this work.

\section{REFERENCES}

Aristotle. (Ed.). (2000). Nicomachean Ethics. Cambridge Texts in the History of Philosophy. Cambridge: Cambridge University Press.

Perry, S.R. (1995). Risk, Harm, and Responsibility. In D.G. Owen (Ed.), Philosophical Foundations of Tort Law (pp. 321-346). Oxford: Clarendon Press.

Rayner, S. (1992). Cultural Theory and Risk Analysis. In S. Krimsky \& D. Golding (Eds.), Social Theories of Risk (pp. 83-115). Westport: Praeger.

van de Poel, I., \& Fahlquist, J.N. (2012). Risk and Responsibility. In S. Roeser, R. Hildebrand, P. Sandin, \& M. Peterson (Eds.), Handbook of Risk Theory (pp. 877-907). 